\title{
CONTROLE PID COM SINTONIA AUTOMÁTICA E ADAPTATIVA DE VÁLVULAS REDUTORAS DE PRESSÃO EM SISTEMAS DE ABASTECIMENTO DE ÁGUA
}

\author{
Anderson SAntos Quadros ${ }^{1}$, André Murilo de Almeida Pinto ${ }^{2}$. \\ 1 Programa de Pós-Graduação em Engenharia Mecânica, Universidade Federal de Pernambuco \\ Av. Arquitetura, s/n - Cidade Universitária - Recife - Brasil - CEP: 50670-901 \\ E-mail: anderson@compesa.com.br
}

\author{
2 Área de Mecatrônica, Departamento de Engenharia Mecânica, Universidade Federal de Pernambuco \\ Av. Arquitetura, s/n - Cidade Universitária - Recife - Brasil - CEP: 50670-901 \\ E-mail: andre.murilo@ufpe.br
}

\begin{abstract}
The real water losses, primarily related to occurrence of leaks, compromise the conservation of water and energy resources and negatively impact the operating and financial performance of water utilities. This paper deals with the control of pressure in water supply systems through the use of Pressure Reducing Valves (PRV) as a final control element to reduce the real losses. The oscillations of the operating pressures in water distribution system, caused by changes in process dynamics and disturbances, are controlled by a PID control system with automatic tuning procedure. For important variations in these characteristics, which can generate significant effects on the dynamic behavior of the control system so that the linear feedback gains with constant coefficients are unable to reach the previously established performance specifications, an adaptive technique with genetic algorithm is also proposed. The simulation results showed the efficiency of this control strategy, held with the use of the mathematical models validated experimentally.
\end{abstract}

Keywords_ Adaptive control, PID control, automatic control, pressure reducing valves, water supply systems.

\begin{abstract}
Resumo- As perdas reais de água, relacionadas principalmente a ocorrência de vazamentos, comprometem a conservação dos recursos hídricos e energéticos e impactam negativamente o desempenho operacional e financeiro das empresas de saneamento. Este trabalho aborda o controle de pressões em sistemas de abastecimento de água, através do uso de válvulas redutoras de pressão como vetor para a redução das perdas reais. As oscilações das pressões de operação nas redes de distribuição, provocadas por variações nas características do processo ou das condições operacionais, são filtradas pelo sistema de controle PID, com sintonia automática, proposto. Para amplas variações destas características, que podem produzir efeitos significativos sobre o comportamento dinâmico do sistema de controle, de forma que os ganhos de realimentação linear e com coeficientes constantes são incapazes de atender às especificações de desempenho previamente definidas, é proposta também a sintonia do controlador com o uso técnica adaptativa por algoritmos genéticos. Os resultados obtidos são demonstrados através de simulações, realizadas com o uso de modelos matemáticos validados experimentalmente.
\end{abstract}

Palavras-chave— Controle adaptativo, controle automático, controle PID, válvulas redutoras de pressão, sistemas de abastecimento

\section{Introdução}

O fraco desempenho das companhias brasileiras de saneamento reflete-se nos indicadores de perdas. De acordo com (RECESA, 2008), o Brasil tem uma média de $40,5 \%$ de perdas totais em seus sistemas de abastecimento de água. As perdas totais englobam tanto as perdas reais, que representam a parcela não consumida devido às fugas de água no sistema, quanto às perdas aparentes, que correspondem à água consumida e não registrada originadas principalmente por ligações clandestinas e erros de medição (LAMBERT; HIRNER, 2000). Aproximadamente a metade das perdas totais está associada às perdas reais, sendo que deste entre $70 \%$ e $90 \%$ ocorrem na rede de distribuição (PNCDA, 2003).

Considerando a grande influência exercida pela pressão da água na ocorrência de vazamentos, diversas empresas de saneamento estão investindo no controle de pressões nas redes de distribuição. Ações voltadas para a setorização das redes, que consiste na divisão da área de abastecimento em áreas menores, complementadas com o uso de Válvulas Redutoras de Pressão (VRP), quando existe excedente de pressão, estão obtendo grande êxito na redução das perdas reais. Além da sua ação na redução do excedente de pressão, as VRP também contribuem no controle de surtos e flutuações abruptas de pressão na rede, sendo que estes últimos fatores influenciam fortemente na ocorrência de vazamentos, estouramentos e desgaste prematuro da rede (PRESCOTT; ULANICKI, 2003).

Neste sentido, este trabalho propõe a aplicação de um sistema de controle, baseado em controlador PID (Proporcional, Integral e Derivativo), com sintonia automática e adaptativa pelos métodos de AstromHagglund e algoritmos genéticos, respectivamente, capaz de melhorar o desempenho da VRP no controle da pressão de jusante. É proposta também uma nova forma de atuação do controlador PID na VRP, por meio de uma válvula proporcional linear.

\section{Modelos}

Nesta seção serão apresentados os modelos e parâmetros de cada elemento da rede de testes ilustrada na Figura 1. Esta rede, igual à apresentada em (PRESCOTT; ULANICKI, 2003), é composta por uma 
fonte de pressão fixa, duas válvulas de bloqueio, uma VRP e quatro tubos. Todos os elementos foram arranjados em série. $\mathrm{O}$ circuito de controle, destacado em vermelho, é composto por um orifício fixo, uma válvula agulha, uma válvula de controle e tubos que conectam estes elementos a VRP. A fonte de pressão fixa pode ser obtida por meio de um sistema de bombeamento ou de reservação de água e as válvulas de bloqueio serão utilizadas para simular alterações nas condições operacionais do sistema.

$$
D_{v}
$$

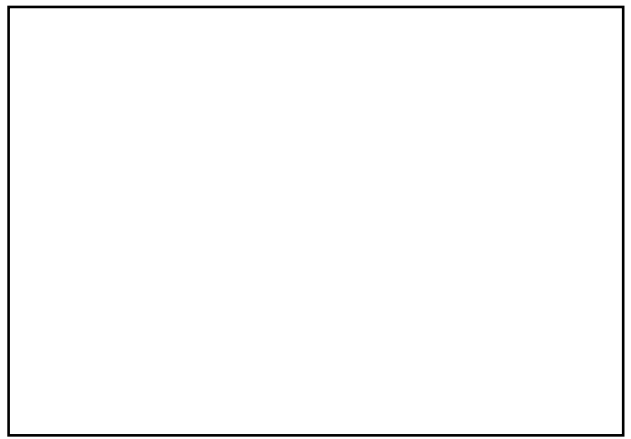


piloto; $\mathrm{a}_{\mathrm{d}}=$ área do diafragma da piloto; $\mathrm{m}_{\mathrm{p}}=$ massa da piloto; $\mathrm{q}_{\mathrm{m}}=$ vazão na VRP; $\mathrm{C}_{\mathrm{vm}}=$ capacidade da VRP; $\mathrm{q}_{1}=$ vazão no orifício fixo; $\mathrm{C}_{\mathrm{vfo}}=$ capacidade do orifício fixo; $\mathrm{p}_{\mathrm{t}}=$ pressão no tê do circuito de controle; $\mathrm{q}_{2}=$ vazão na piloto; $\mathrm{C}_{\mathrm{vp}}=$ capacidade da piloto, que varia em função da abertura, é disponibilizado pelo fabricante ou medido experimentalmente; $\mathrm{C}_{\mathrm{vnv}}=$ capacidade da válvula agulha; $\mathrm{p}_{\mathrm{c}}=$ pressão na câmara de controle. Assim como em (PRESCOTT; ULANICKI, 2003), nas simulações serão utilizados os seguintes parâmetros e variáveis: $\mathrm{a}_{1}=0,0078 \mathrm{~m}^{2}$, $\mathrm{a}_{2}=0,0218 \mathrm{~m}^{2}, \quad \mathrm{a}_{\mathrm{d}}=0,00196 \mathrm{~m}^{2}, \quad \mathrm{~m}_{\mathrm{m}}=8 \mathrm{~kg}, \quad \mathrm{C}_{\mathrm{vnv}}=$ $1 \cdot 10^{-5}, C_{v f o}=3 \cdot 10^{-5}$, capacidade e área de seção transversal da câmara de controle da VRP:

$$
\begin{gathered}
C_{v m}\left(x_{m}\right)=0,02107-0,02962 e^{-51,1322 x_{m}}+0,0109 e^{-261 x_{m}} \\
-0,00325 e^{-683,17 x_{m}}+0,0009 e^{-399,5 x_{m}} \\
A_{c S}\left(x_{m}\right)=\frac{1}{3700\left(0,02732-x_{m}\right)}
\end{gathered}
$$

\subsection{Modelo da Válvula com Característica Linear}

Este trabalho propõe uma inovação em relação à forma de atuação do sistema de controle na VRP. As soluções existentes utilizam válvulas piloto com diafragma, com algum tipo de adaptação mecânica, válvulas solenoides do tipo on/off ou uma combinação destas. Neste trabalho será proposta a utilização de uma válvula elétrica do tipo linear para reproduzir o comportamento da válvula piloto. Esta modificação tem como principal objetivo o estabelecimento de uma relação direta entre o sinal de controle do controlador PID (abertura da válvula $\left(x_{p p}\right)$ ) e as equações do modelo fenomenológico simplificado da VRP, visto que o sinal de controle será aplicado diretamente na válvula linear e este influenciará a vazão $q_{3}$ pela modulação da vazão $q_{2}$, conforme pode ser observado nas Equações 9, 10 e 11 .

Para o desenvolvimento do modelo da válvula linear, foi utilizada como referência a válvula solenoide proporcional modelo Posiflow, série G202 do fabricante $\mathrm{ASCO}^{\circledR}$ (ASCOVAL, 2012). A válvula selecionada possui conexão com o processo de 1/4", orifício interno de $3,2 \mathrm{~mm}$ e capacidade de vazão $\left(\mathrm{C}_{\mathrm{vpp}}\right)$ de 0,2808 . Desta forma, o $\mathrm{C}_{\mathrm{vpp}}\left(\mathrm{x}_{\mathrm{pp}}\right)$ da válvula linear será dado por:

$$
C_{v p p}\left(x_{p p}\right)=0,2808 x_{p p}
$$

Onde: $\mathrm{C}_{\mathrm{vpp}}=$ capacidade da válvula linear; $\mathrm{x}_{\mathrm{pp}}=$ abertura da válvula linear (sinal de controle PID). Nas simulações dos sistemas de controle, este coeficiente será utilizado na Equação 9 e a Equação 6, que representa o comportamento da válvula piloto mecânica, não será utilizada.

\subsection{Modelos das Tubulações e Válvulas de Bloqueio}

Para simular o escoamento na rede hidráulica, que estará sujeita a pequenas perturbações, será utilizado o método da coluna rígida. A equação diferencial não linear de movimento do modelo da coluna rígida é apresentada abaixo (WYLIE; STREETER, 1993).

$$
\dot{q}=\frac{g A}{L}\left(p_{m}-p_{j}-f_{D W} \frac{L}{D} \frac{v^{2}}{2 g}\right)
$$

Onde: $f_{D W}=$ coeficiente de Darcy-Weisbach; $v=$ velocidade do fluido. A Equação 15, juntamente com a equação da continuidade e das equações de contorno, descrevem a dinâmica do fluxo transiente pelo modelo da coluna rígida. As tubulações da rede de teste possuem comprimentos de $1,5 \mathrm{~m}, 4 \mathrm{~m}, 5 \mathrm{~m}$ e $6 \mathrm{~m}$ e diâmetros de $0,05 \mathrm{~m}, 0,1 \mathrm{~m}, 0,1 \mathrm{~m}$ e $0,1 \mathrm{~m}$, respectivamente.

O comportamento das válvulas de bloqueio será representado pela equação de Darcy-Weisbach.

$$
q=c a \sqrt{2 g\left(p_{m}-p_{j}\right)}
$$

Onde c = coeficiente de descarga; $a$ = área de seção transversal do orifício. Em todas as simulações foram utilizadas válvulas de bloqueio com a $=0,007854 \mathrm{~m}^{2}$.

\section{Sistema de Controle}

Considerado de longe o mais popular algoritmo de controle, muitos sistemas de controle com realimentação utilizam controladores PID. Segundo (ASTROM; HAGGLUND, 1995), a versão acadêmica do controlador PID possui a seguinte forma:

$$
\begin{aligned}
& u(t)=K_{p} e(t)+K_{i} \int_{0}^{t} e(\tau) d \tau+K_{d} \frac{d e(t)}{d t} \\
& e(t)=y_{s p}(t)-y(t)
\end{aligned}
$$

Onde: $u(t)$ é o sinal de controle, $e(t)$ é o erro de controle, $y(t)$ é o valor medido da saída do processo e $y_{s p}(t)$ é o valor do setpoint. A variável de controle é formada pela soma dos termos Proporcional, Integral e Derivativo. O ganho proporcional $K_{p}$, a constante integral $K_{i}$, e a constante derivativa $K_{d}$ são os parâmetros do controlador.

A escolha do método para determinação dos parâmetros do controlador PID está diretamente relacionada com os requisitos de desempenho estabelecidos para o controlador e com a dinâmica do processo (ASTROM; HAGGLUND, 1995). Se a dinâmica é constante, deve-se adotar um controlador com parâmetros constantes, sintonizado por algum método de sintonia automática. Neste caso, será utilizado neste trabalho o método do relé de AstromHagglund. Para dinâmicas variáveis e variações imprevisíveis, outros métodos de sintonia capazes de se adaptarem continuamente devem ser utilizados. Para 
esta situação, será utilizado o algoritmo genético neste trabalho.

Nas simulações foram realizadas no MatLab $^{\circledR} /$ Simulink $^{\circledR}$ com o período fixo de amostragem de $0,01 \mathrm{~s}$, em um computador pessoal padrão com processador de 32bits e núcleo duplo de $2 \mathrm{GHz}$ e memória RAM de 2GB.

Para a validação dos resultados, será adotado um cenário de simulação que reproduzirá o comportamento típico de um setor de abastecimento composto por consumidores residenciais e industrial, caracterizado por um perfil de consumo formado pela adição de pequenas e constantes variações com uma grande variação na demanda. Para reproduzir este comportamento na rede de teste, será somado um sinal com pequenas e sucessivas variações a outro que aplicará grande variação no coeficiente de descarga da válvula de bloqueio localizada à jusante da VRP. O sinal com pequenas variações possui média de 0,03 e variância 0,001 . O outro sinal, no intervalo de tempo [0 30 s] possui valor constante de 0,02 , entre 30 s e $32 \mathrm{~s}$ aumenta linearmente para 0,04 e permanece com este valor até $120 \mathrm{~s}$. O sinal aplicado ao coeficiente de descarga da válvula de bloqueio localizada à jusante da VRP é apresentado na Figura 3.

Para todas as simulações utilizou-se coeficiente de descarga para a válvula de bloqueio de montante de 0,15 e setpoint de $38,81 \mathrm{~m}$.

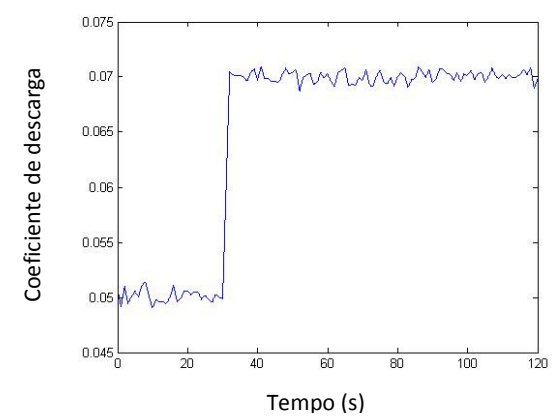

Figura 3: Perfil de abertura da válvula de bloqueio de jusante.

\subsection{Sintonia Automática do Controlador PID pelo Método do Relé de Astrom-Hagglund}

O método de Astrom e Hagglund consiste na inserção de um relé, no lugar do controlador, e a amplitude deste é ajustada até que o erro apresente oscilações com amplitude e período constantes, com período $T_{c r}$. Se $d$ é a amplitude do relé, da expansão em série de Fourier, tem-se que o primeiro harmônico da saída do relé tem amplitude $4 d / \pi$. Com a amplitude da saída do processo sendo a, tem-se o ganho crítico.

$$
K_{C R}=\frac{4 d}{\pi a}
$$

O período crítico pode ser determinado pela contagem de tempo entre passagens por zero da saída do sistema. De posse do $K_{c r}$ e do $T_{c r}$, a margem de fase será adotada para a determinação dos parâmetros do controlador PID (ASTROM; HAGGLUND, 1983). Neste caso, as seguintes relações devem ser utilizadas para o cálculo dos parâmetros PID:

$$
\begin{aligned}
& K_{p}=K_{c r} \cos \emptyset_{m} \\
& K_{d}=K_{p}\left(\frac{\tan \emptyset_{m}+\sqrt{\tan ^{2} \emptyset_{m}+\frac{4}{\alpha}}}{2 w_{c r}}\right) \\
& K_{i}=\frac{K_{p}^{2}}{\alpha K_{d}}
\end{aligned}
$$

Onde: $\emptyset_{\mathrm{m}}$ é a margem de fase e $\alpha$ é uma constante, que representa um fator de correção para o cálculo do tempo integral.

Para alcançar as oscilações com período e amplitude constantes no sinal de erro, a amplitude do relé $(d)$ foi incrementada até 0,0003 . Com estes valores, as equações 17, 18, 19 e 20 foram aplicadas para a obtenção dos parâmetros do controlador PID. Os valores dos parâmetros calculados, assim como os parâmetros utilizados e obtidos na simulação da rede de testes, foram: $K_{p}=7,24.10^{-5}, K_{i}=1,91.10^{-4}, K_{d}=$ $2,74 \cdot 10^{-5}, \emptyset_{\mathrm{m}}=60^{\circ}, \alpha=1$.

\subsection{Sintonia Adaptativa do Controlador PID por Algoritmos Genéticos}

Apesar de não haver uma estrutura padrão, a maioria dos algoritmos genéticos descritos na literatura adota os mesmos componentes básicos (HAUPT; HAUPT, 2005): definição de parâmetros e variáveis, geração da população inicial, seleção, cruzamento e mutação.

O primeiro passo, na busca pela solução ótima, é a definição das variáveis do problema. Cada variável será representada como um gene de um cromossomo, também denominado indivíduo. Desta forma, cada cromossomo será um vetor contendo valores das variáveis (genes) a serem otimizadas. Neste artigo, os genes representarão os ganhos Proporcional, Integral e Derivativo do Controlador PID.

Definidas as variáveis, determinam-se os parâmetros do algoritmo e o critério de desempenho que será utilizado para avaliar o custo de cada cromossomo. Tamanho da população, taxa de cruzamento, taxa de mutação, taxa de seleção, custo e quantidade máxima de iterações são parâmetros geralmente utilizados.

Escolhidos as variáveis e os parâmetros do algoritmo, determina-se a população inicial de indivíduos. A população inicial será formada aleatoriamente, dentro dos intervalos definidos pelos ganhos máximos e mínimos, conforme a metodologia indicada na Equação 23.

$$
\text { gan }=\left(g_{\text {máx }}-g a n_{m i ́ n}\right) * r+g a n_{\text {mín }}
$$

Onde: gan = ganho PID, $\mathrm{r}$ é um valor aleatório escolhido no intervalo $[0,1]$. 
Gerada a população inicial, o custo associado a cada indivíduo, relacionado ao critério de desempenho adotado, é calculado e é realizada uma ordenação do menor para o maior custo. Apenas uma fração dos indivíduos, definida pela taxa de seleção, é selecionada para a geração da nova população através da realização de cruzamentos. Os indivíduos mais fracos são eliminados. Neste artigo, será adotado para o cálculo do custo o critério da integral do erro absoluto ponderado pelo tempo (ITAE).

Selecionados os melhores indivíduos, inicia-se o processo de cruzamento. Para a realização dos cruzamentos, os indivíduos pais serão selecionados aleatoriamente no conjunto de indivíduos melhores avaliados pela função custo e delimitado pela taxa de seleção. Selecionados os pais, de forma a prover uma maior exploração do espaço de busca, com a inserção de material genético nos filhos diferente dos materiais dos pais, será adotado o método proposto por (HAUPT; HAUPT, 2005). Neste método, inicialmente são atribuídos os materiais genéticos dos pais aos filhos, conforme apresentado na Equação 24.

$$
\begin{aligned}
\text { filho1 } & =\left[\begin{array}{lll}
g_{m 1} & g_{m 2} & g_{m 3}
\end{array}\right] \\
\text { filho2 } & =\left[\begin{array}{lll}
g_{p 1} & g_{p 2} & g_{p 3}
\end{array}\right]
\end{aligned}
$$

Onde: $g_{m i}=$ gene i da mãe, $g_{p i}=$ gene i do pai.

Em seguida, é realizada a seleção aleatória do ponto, denominado ponto de corte, em que será inserido o novo material genético nos filhos. Selecionado o ponto de corte, o novo material genético é calculado conforme a Equação 25.

$$
\begin{aligned}
& g_{\text {novo1 }}=g_{m p c}-r\left(g_{m p c}-g_{p p c}\right) \\
& g_{\text {novo2 }}=g_{p p c}+r\left(g_{m p c}-g_{p p c}\right)
\end{aligned}
$$

Onde: $r$ é um valor aleatório escolhido no intervalo $[0,1], g_{m p c}=$ gene da mãe no ponto de corte, $g_{p p c}=$ gene do pai no ponto de corte.

A finalização do cruzamento se dá com a inserção do gene novo e a realização da troca de genes com o irmão, conforme apresentado na Equação 26.

$$
\begin{aligned}
& \text { filho1 }=\left[\begin{array}{lll}
g_{m 1} & g_{\text {novo } 1} & g_{p 3}
\end{array}\right] \\
& \text { filho2 }=\left[\begin{array}{lll}
g_{p 1} & g_{\text {novo }} & g_{m 3}
\end{array}\right]
\end{aligned}
$$

O operador mutação é aplicado de forma aleatória no material genético de uma fração dos indivíduos da população, definida pela taxa de mutação. Na mutação, os indivíduos e os genes serão selecionados aleatoriamente dentre todos os indivíduos e genes da população. Uma vez selecionados, é aplicada a mesma metodologia apresentada na Equação 23 para a substituição dos genes selecionados.

O supracitado processo, conforme ilustrado no fluxograma, é repetido de forma iterativa até que o critério de parada seja atingido.

\section{Resultados e Discussões}

Nesta seção serão apresentados os resultados obtidos com as simulações da VRP controlada pela válvula piloto e pelos controladores PID sintonizados pelos métodos de Astrom-Hagglund e algoritmos genéticos.

Para comparar a eficiência dos métodos de sintonia supracitados serão utilizados os seguintes parâmetros de desempenho: tempo de simulação, custo (ITAE), média, variância, máximo e mínimo.

\subsection{Comportamento da VRP com a válvula piloto}

Aplicados os modelos, sinais e parâmetros apresentados nas seções anteriores, o resultado obtido para a pressão de jusante da válvula com a VRP controlada pela válvula piloto é apresentado na Figura 4.

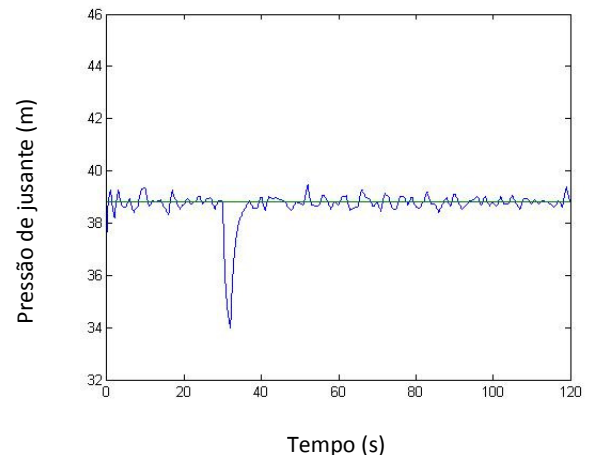

Figura 4: Perfil de pressão de jusante da VRP com a válvula piloto.

Nesta simulação, realizada em $1,71 \mathrm{~s}$, foram obtidos os seguintes valores para os parâmetros de desempenho: custo $=1,32.10^{5}$, média $=38,7072$, variância $=0,3511$, máximo $=39,4567$, mínimo $=$ 33,9803 .

\subsection{Sintonia pelo Método de Astrom-Hagglund}

O resultado obtido para a pressão de jusante da válvula, com a aplicação do controlador PID sintonizado pelo método de Astrom-Hagglund, é apresentado na Figura 5 .

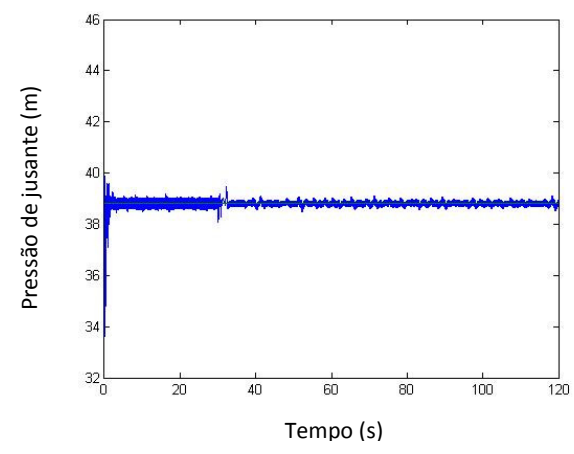

Figura 5: Perfil de pressão de jusante da VRP com a sintonia pelo Astrom-Hagglund. 
Nesta simulação, realizada em 6,31s, foram obtidos os seguintes valores para os parâmetros de desempenho: custo $=8,36.10^{4}$, média $=38,8106$, variância $=0,0228$, máximo $=39,4552$, mínimo $=$ 38,0671 .

\subsection{Sintonia por Algoritmos Genéticos}

Para a aplicação do algoritmo genético na sintonia do controlador PID foram adotados os seguintes parâmetros: tamanho da população $=20$, taxa de mutação $=10 \%$, taxa de seleção $=50 \%$, quantidade máxima de iterações $=5$ e custo mínimo $=1.10^{3}$.

$\mathrm{O}$ resultado obtido para a pressão de jusante da válvula, com a aplicação do controlador PID no sistema, é apresentado na Figura 6.

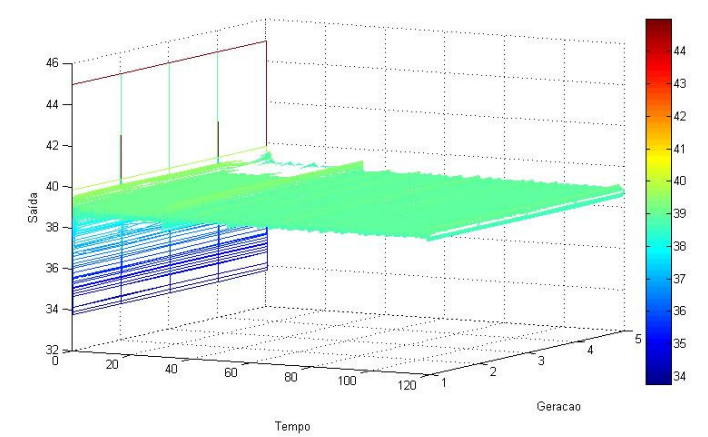

Figura 6: Pressão de jusante da VRP com o algoritmo genético.

Os parâmetros ótimos do controlador obtidos, em relação ao custo, foram $K_{p}=7,89.10^{-5}, K_{i}=2.10^{-4}$ e $K_{d}$ $=1,74 \cdot 10^{-4}$.

Nesta simulação, realizada em 402,33s, foram obtidos os seguintes valores para os parâmetros de desempenho: custo $=8,37.10^{4}$, média $=38,8104$, variância $=0,0224$, máximo $=39,2188$, mínimo $=$ 38,1028 .

\section{Conclusões}

Este trabalho apresentou o desenvolvimento de sistemas de controle PID, sintonizados pelos métodos de Astrom-Hagglund e por algoritmos genéticos, aplicados a VRP para o controle de pressões em redes de distribuição de água. Também foi proposta uma nova forma de atuação do controlador na VRP, com o uso de válvulas lineares.

As simulações realizadas demonstraram a aplicabilidade dos métodos de sintonia propostos. Todos os indicadores de desempenho da VRP controlada pelos controladores PID foram melhorados em relação à VRP com a válvula piloto. Melhorias significativas foram obtidas para o desvio da média em relação ao setpoint e para a variância, alcançando-se reduções em relação à VRP com a piloto, de 99,61\% e $93,62 \%$ respectivamente. Foi verificado também que o método de sintonia por algoritmo genético apresentou os melhores resultados em relação aos métodos anteriores. É importante ressaltar que, devido ao maior esforço computacional requerido e a capacidade de adaptação contínua, a utilização do algoritmo genético é mais indicada para os casos em que o sistema estará sujeito a grandes e imprevistas variações na dinâmica. Destaca-se também que para a aplicação dos métodos de sintonia propostos não se fez necessária a utilização de modelos do processo para a determinação dos parâmetros do controlador.

Verificou-se também que este trabalho representa um avanço em relação ao trabalho apresentado por (PRESCOTT; ULANICKI, 2008) quanto à forma de atuação e de sintonia do controlador PID.

\section{Referências Bibliográficas}

ASCOVAL INDÚSTRIA E COMÉRCIO LTDA. Válvula solenoide proporcional posiflow. Catálogo do fabricante. Disponível em < http://www.ascoval.com.br/literatura/FluidControl/ 31B/catalogo/126_G202.pdf >. Acessado em: ago. 2012.

ASTROM, K.J; HAGGLUND, T. Automatic tuning of simple regulators with specifications on phase and amplitude margins. IFAC Workshop on Adaptive Systems in Control and Signal Processing, San Francisco, California, U.S.A., 1983.

ASTROM, K.J; HAGGLUND, T. PID controllers: theory, design and tuning. Instrument Society of America, $2^{\mathrm{a}}$ ed. 1995. 343p.

HAUPT, R. L.; HAUPT, S. E. Practical genetic algorithms. $2^{\mathrm{a}}$ ed. A Wiley-Interscience publication, Hoboken, New Jersey, 2005.

LAMBERT A.; HIRNER W. Losses from water supply systems: standard terminology and recommended performance measures. International Water Association. The blue pages. London, 2000.

PNCDA - Programa Nacional de Combate ao Desperdício de Água. Documento de Apoio Técnico $\mathrm{n}^{\mathrm{0}} \mathrm{A} 2$. Indicadores de perdas nos sistemas de abastecimento de água. Brasília, 2003. 80p.

PRESCOTT, S. L.; ULANICKI, B. Dynamic modeling of pressure reducing valves. Journal of hydraulic engineering - ASCE, Vol. 129, No 10, Out. 2003.

PRESCOTT, S. L.; ULANICKI, B. Improved control of pressure reducing valves in water distribution networks. Journal of hydraulic engineering - ASCE, Vol. 134, N 1, Jan. 2008.

DOI: 10.1061/(ASCE)0733-9429(2008)134:1(56)

RECESA - Rede de Capacitação e Extensão Tecnológica em Saneamento Ambiental. Núcleo Regional Nordeste - NURENE. Abastecimento de água: gerenciamento de perdas de água e energia elétrica em sistemas de abastecimento: nível 2 / Secretaria Nacional de Saneamento Ambiental. Salvador, 2008. 139p.

WYLIE, E.B.; STREETER, V. L. Fluid Transients in Systems. Prentice-Hall, Upper Saddle River, New Jersey, Estados Unidos, 1993. 